\title{
Forecasting the Rainfall Pattern on Upstream of Hirakud Reservoir Using L-Moment for Accessing the Inflow
}

\author{
Krishna Kumar Gupta1, Anil Kumar Kar'2, Joygopal Jena33, Dipti Ranjan Jena4 \\ ${ }^{1}$ Civil Engineering Department, SOA University, Bhubaneswar, India \\ ${ }^{2}$ VSSUT, Burla, Sambalpur, India \\ ${ }^{3}$ Civil Engineering GITA, Bhubaneswar, India \\ ${ }^{4}$ Department of Geography, Utkal University, Bhubaneswar, India \\ Email:kkg_2010@rediffmail.com, anilkarhy@gmail.com,jenajoygopal@gmail.com,diptiluna@gmail.com
}

How to cite this paper: Gupta, K.K., Kar, A.K., Jena, J. and Jena, D.R. (2017) Forecasting the Rainfall Pattern on Upstream of Hirakud Reservoir Using L-Moment for Accessing the Inflow. Journal of Water Resource and Protection, 9, 1335-1346. https://doi.org/10.4236/jwarp.2017.912085

Received: September 15, 2017 Accepted: November 10, 2017 Published: November 13, 2017

Copyright (c) 2017 by authors and Scientific Research Publishing Inc. This work is licensed under the Creative Commons Attribution International License (CC BY 4.0).

http://creativecommons.org/licenses/by/4.0/

\begin{abstract}
Changes in the rainfall pattern are a challenge for filling schedule of reservoir, when it is fulfilling various demands. In monsoon fed reservoirs, the target remains for attaining full reservoir capacity in order to meet various demands during non-monsoon period and the flood control. The planners always eye towards the inflow trend and perspective frequency of rainfall in order to counter the extreme events. In this study, the case of Hirakud reservoir of Mahanadi basin of India is considered as this reservoir meets various demands as well as controls devastating floods. The inflow trend has been detected by using Mann Kendall test. The frequency analysis of monthly rainfall is calculated using L-moment program for finalizing a regional distribution. The falling trend in inflow to reservoir is visualized in the month of July and August. The Wakeby distribution is found suitable for the monthly rainfall of July, September and October, where as in June and August, General Extreme Value (GEV), General Normal (GN) and Pearson Type-III (PT-III) distributions are found suitable. The regional growth factors for the 20, 40, 50 and 100 -year return period rainfalls along with inflow to reservoir observed between 1958-2010 are calculated in this study as a referral for reservoir operation policy.
\end{abstract}

\section{Keywords}

Hirakud Reservoir, Trend Analysis, L-Moment, General Normal (GN), General Logistic (GL) Wakeby Distribution, GEV

\section{Introduction}

Hirakud reservoir as a multipurpose dam resolving many demands of state of 
Odisha. The operation of the reservoir is governed by a specified rule curve and it is supposed to attain its full reservoir level at the end of October 31st (end of monsoon season) in order to meet the demands till start of the monsoon season (end of May). In this regard the rainfall and its distribution of upstream districts play pivotal role in filling schedule of the reservoir. There are numbers of studies in these regards and a few of them are discussed. Reference [1] shows the characteristics of Miyun reservoir of China. It was found that annual inflow, flood peaks decreases in both quantity and proportion and this decreasing extent is higher than that of common runoff. Human activities like high population growth and corresponding land use changes remain the major concern. Forecasting of future water availability to meet conflicting demands is the major task. Under this study [2] seasonality, stochasticity and non-linearity of the inflow were identified. Reference [3] has analysed the effect of climate change for northern reservoirs of Indiana using Self Organisation Map (SOM) to perform trend and cluster analysis. The Mann Kendall and Revised Mann Kendall were used for regionalization. Another study [4] made on a saline reservoir of state Odisha, India which focused on trend analysis of rainfall using Mann Kendall, inflow quantification using ARNO model and performance evaluation of reservoir using WEAP model under changing climatic situations. Reference [5] has studied about trends in water quality and quantity for 11 major reservoirs of the Brazos and Colorado river basins in the southern Great Plains. The components like water quality, major contributing-stream inflow, storage, local precipitation, and basin-wide total water withdrawals were analyzed. The study of [6] has applied the Mann-Kendall (MK) statistical trend test on a wide range to analyze increasing, decreasing or trendless characteristics of precipitation, temperature, inflow to dam reservoirs, release from dam reservoirs, and storage volume in dam reservoir in Thailand from historical operation recorded data. As per [7], reservoir inflow corresponding to varying rainfall pattern under climate change conditions causing the variation of the reservoir inflow. They have proposed a hybrid SD model named Wavelet Support Vector Machine (WSVM) in combination of the multiscale Principal Components Analysis (MSPCA) and nonlinear Support Vector Machine regression model for Sutami Reservoir, Indonesia and found that WSVM shown better result in inflow forecasting.

L-moment approach has been applied to many events in number of cases for finding parent distribution. In case of flood frequency analysis L-moment has been applied in many occasions. However, in different rainfall events application of L-moment is seen in cases like [8], found that the frequency analysis of the largest or the smallest of a sequence of hydrologic events has long been an essential part of the design of hydraulic structure. Reference [9] has used L-moment for regionalization of annual precipitation in northern Central Italy. Reference [10] has applied L-moment for selection of parent distribution to fit maximum monthly rainfall data of 18 sites of the Zayanderhood basin, Iran. The obtained extreme rainfall values can be used for meteorological drought management in the arid zone. Reference [11] has applied L-moment for probability distribution 
of extreme value 1-day rainfall events.

\section{Study Area}

The Hirakud reservoir of Mahanadi basin cover almost 83,400 sq km of catchment area out of total catchment of $141,589 \mathrm{sq} \mathrm{km}$ and covering most part of two states like Chhatisgarh and Odisha (Figure 1).

The reservoir Hirakud was commissioned since 1958 as a multipurpose project. A catchment of $83,400 \mathrm{sq} \mathrm{km}$ drains into reservoir Hirakud covering 24 districts of four states fully or partly (Figure 2). The reservoir is monsoon fed and its storage of 4825 Mcum is being utilized for number of demands like irrigation, hydropower, industrial, domestic, environment and more. The reservoir has immense importance towards the economic development of the state. The monsoon generally breaks during the mid and latter June in the states of Chhatisgarh and Odisha, inflow starts entering into reservoir and the flow continues till end of October. As the both the states are developing fast, definitely there will be certain changes in the landuse pattern which may put direct impact on the inflow to reservoir. The climatic changes also showed lot of spatio-temporal variation in the rainfall patterns. Considering above facts, this study is done for

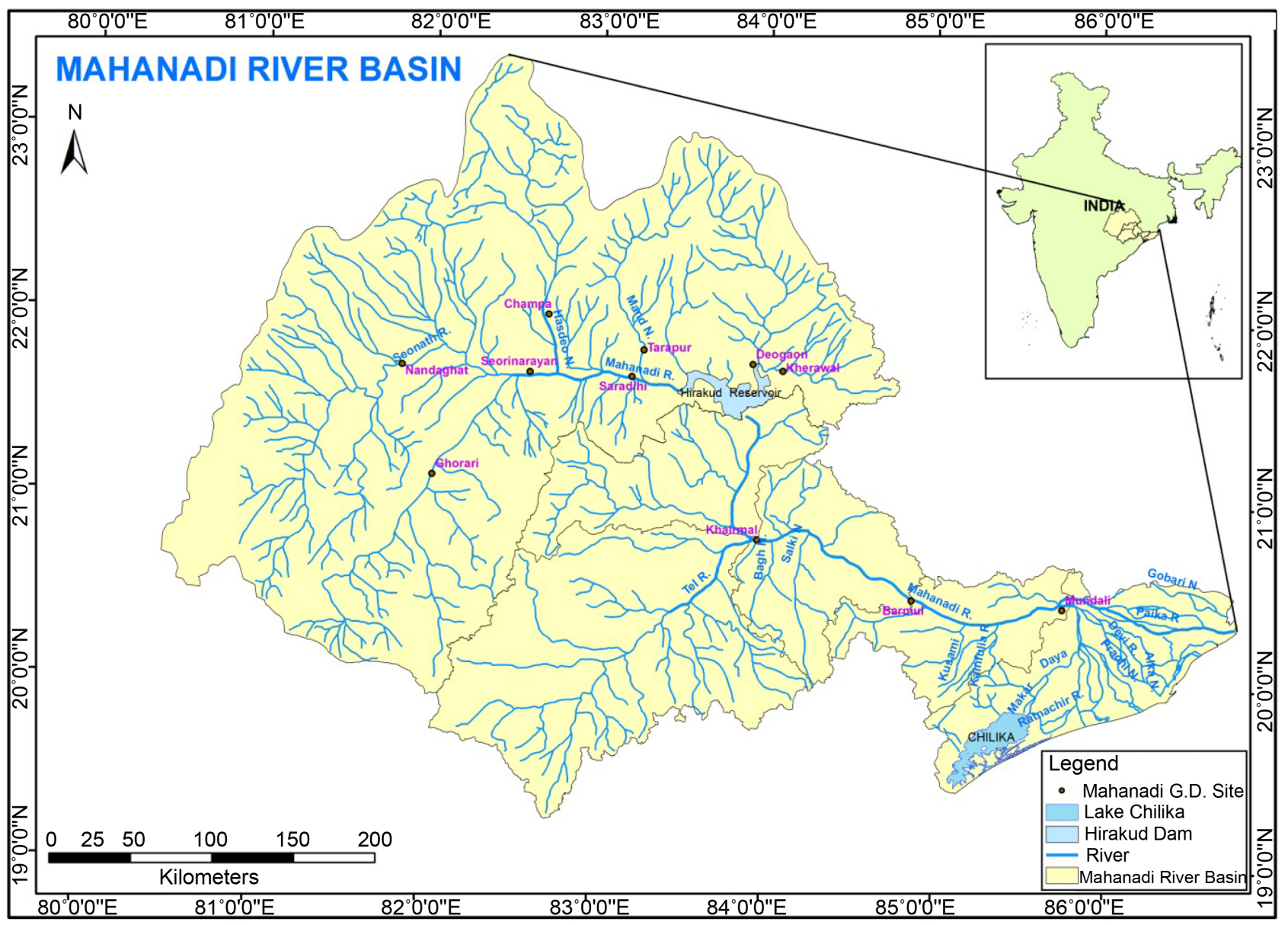

Figure 1. Mahanadi basin with Hirakud reservoir. 


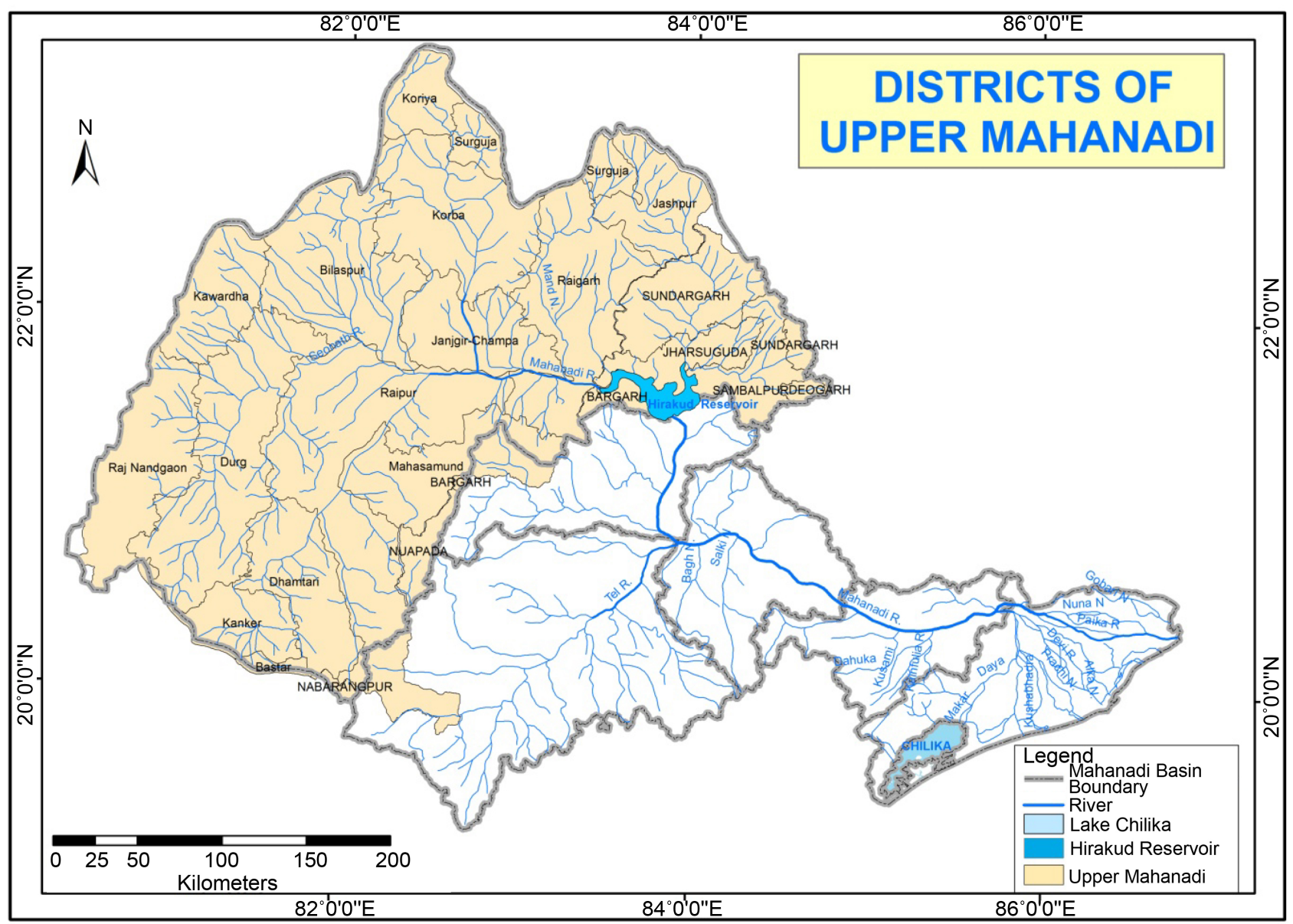

Figure 2. Mahanadi catchment showing districts of upper catchment.

searching a trend in rainfall and inflow as it may has been put direct impact on the operation and management of reservoir for fulfilling the necessary demands. As the study is related to inflow of reservoir, districts of its upstream part are only considered.

\section{Methodology}

1) Trend Detection: To identify trend in climatic variables with reference to climate change, the Mann-Kendall test has been employed by a number of researches with temperature, precipitation and stream flow data series ([12] [13] [14] [15] [16]). It is a common practice to use a non-parametric test to detect a trend in a time series. This test, being a function of the ranks of the observations rather than their actual values, is not affected by the actual distribution of the data and is less sensitive to outliers. On the other hand, parametric trend tests, although more powerful, require the data to be normally distributed and are more sensitive to outliers. The Mann-Kendall test is therefore more suitable for detecting trends in hydrological time series, which are usually skewed and may be contaminated with outliers. This test has been extensively used with environmental time series [17]. 
The Mann-Kendall trend test is based on the correlation between the ranks of a time series and their time order. For the statistics $S$ is calculated as Equation (1). This statistic represents the number of positive differences minus the number of negative differences for all the differences considered as

$$
S=\sum_{i=1}^{n-1} \sum_{j=i+1}^{n} \operatorname{sgn}\left(x_{j}-x_{i}\right)
$$

where, $n$ is the number of total data points, $x_{i}$ and $x_{j}$ are the data values in time series $i$ and $(j>i)$, respectively, and $\operatorname{sgn}\left(x_{j}-x_{i}\right)$ is the sign function as:

$$
\operatorname{sgn}\left(x_{j}-x_{i}\right)= \begin{cases}+1, & \text { if }\left(x_{j}-x_{i}\right)>0 \\ 0, & \text { if }\left(x_{j}-x_{i}\right)=0 \\ -1, & \text { if }\left(x_{j}-x_{i}\right)<0\end{cases}
$$

The variance of Mann- Kendall test is calculated by Equation (3) as

$$
\operatorname{Var}(S)=\frac{n(n-1)(2 n+5)-\sum_{i=1}^{m} t_{i}\left(t_{i}-1\right)\left(2 t_{i}+5\right)}{18}
$$

where, $n$ is the number of total data points, $m$ is the number of tied groups. The tied group means a simple data having a same value. The $t_{i}$ indicates the number of ties of extent, $i$. In case of the sample size, $n>10$, the standard normal test statistic $Z_{s}$ is estimated by Equation (4) as

$$
Z_{s}= \begin{cases}\frac{S-1}{\sqrt{\operatorname{Var}(S)}}, & \text { if } S>0 \\ 0, & \text { if } S=0 \\ \frac{S+1}{\sqrt{\operatorname{Var}(S)}}, & \text { if } S<0\end{cases}
$$

The positive values of $Z_{s}$ show increasing trends while negative values represent falling trends. As $5 \%$ significance level is taken standard for this study, the null hypothesis of no trend is rejected if $\left|Z_{s}\right|>1.96$.

2) L-moment analysis: Three statistical measures discordancy measure, heterogeneity measure and goodness of fit measure as per L-moment approach are used in regional studies. These measures are explained by [18]. It is used to estimate the degree of heterogeneity and to assess whether they might reasonably be treated as homogeneous. Specifically, the heterogeneity measure compares between site variations in sample L-moments for the group of sites with that expected for a group of region. Hosking's Heterogeneity test fits 4 parameter Kappa distributions. A series of 500 simulations $\left(N_{\text {sim }}\right)$ done and L-statistics of actual region is compared with a simulated series. The $H$-statistics defined as,

$$
H_{i}=\left(V_{i}-\mu_{v}\right) / \sigma_{v}
$$

For each simulated region, the measures of variability $V_{i}$ (where $V_{i}$ is any of three measures $V_{1}, V_{2}$ and $V_{3}$ ) is calculated. From the simulated data, the mean $\mu_{v}$ and standard deviation $\sigma_{v}$ of the $N_{\text {sim }}$ values of $V_{i}$ are determined. 
The critical $H$ statistics for a region to be homogeneous is as mentioned below

$H<1$ Homogeneous

$1 \leq H \leq 2$ Possibly heterogeneous

$H>2$ Definitely heterogeneous

Reference [12] has observed that statistics $H_{2}$ and $H_{3}$ based on measure of $V_{2}$ and $V_{3}$ lack the power to discriminate between homogeneous and heterogeneous regions but $H_{1}$ based on $V_{1}$ has much better discriminating power. So $H_{1}$ is treated as a much better indicator of heterogeneity measure. Also, $H_{1}$ was found to be a better indicator of heterogeneity in large regions, but has a tendency to give false indication of homogeneity for small regions [19].

The measure $\mathrm{H}_{2}$ indicates whether at-site and regional estimates will be close to each other. A large value of $\mathrm{H}_{2}$ indicates whether or not the at-site and regional estimates will be in agreement, whereas a large value of $H_{3}$ indicates a large deviation between at-site estimates and observed data.

3) Selection of Regional Distribution: The regional distribution has been adjudged on the basis of Z-statistics as follows:

It indicates suitability of a candidate distribution to a data series and is appropriate for evaluating and comparing a distribution. The $Z$-statistics for the goodness of fit measure as defined by Hosking is

$$
Z^{D I S T}=\left(Z_{4}^{D I S T}-Z_{4}+B_{4}\right) / \sigma_{4}
$$

$D I S T=$ a particular distribution, $Z_{4}^{D I S T}=$ L-kurtosis for fitted distribution, $Z_{4}=$ pooled L-kurtosis, $B_{4}=$ bias correction, $\sigma_{4}=$ estimate of sample variability of L-kurtosis. The $Z^{\text {DIST }}$ value should be close to zero. However, a value between -1.64 and 1.64 is considered to be suitable for a fitting distribution at $10 \%$ significance level. While a number of distributions may qualify the goodness-of-fit criteria, the most potential will be one that has minimum $\left|Z^{D I S T}\right|$ value. The rainfall values based on different frequencies are calculated from the relationship between $R_{t}$ and $R_{m}$, where $R_{t}$ is the rainfall value at particular return period $t$ and $R_{m}$ is the mean rainfall.

Data Used: The district wise rainfall data from 1958-2010 is used from the India Meteorological Department (IMD) sources and the Inflow to reservoir has been obtained from Government of Odisha [20].

\section{Results and Discussion}

From the catchment map (Figure 2) it is found that, there are 23 districts in the upstream catchment of Hirakud reservoir out of them 7 districts comprising $13.10 \%$ of upstream catchment belongs to Odisha state. Chhatisgarh has 15 districts occupying $86.54 \%$ of the same.

As the upstream catchment analysis is needed for finding the inflow characteristics first of all the influence area of each districts which is influencing the inflow are obtained and mentioned in Table 1. 
Table 1. Influence area of Upstream districts.

\begin{tabular}{|c|c|c|}
\hline Districts & Area (sq km) & Influence area (\%) \\
\hline & Odisha & \\
\hline Bargarh & 800.06 & 0.96 \\
\hline Deogarh & 296.83 & 0.36 \\
\hline Jharsuguda & 2121.48 & 2.54 \\
\hline Nabarangapur & 189.44 & 0.23 \\
\hline Nuapada & 968.92 & 1.16 \\
\hline Sambalpur & 2406.83 & 2.89 \\
\hline S.Garh & 4140.66 & 4.97 \\
\hline \multirow[t]{2}{*}{ Total } & & 13.10 \\
\hline & Chhatisgarh & \\
\hline Bastar & 370.89 & 0.44 \\
\hline Bilaspur & 6742.00 & 8.09 \\
\hline Dhmatari & 4087.37 & 4.90 \\
\hline Durg & 8660.60 & 10.39 \\
\hline Janjgir-Champa & 3890.36 & 4.67 \\
\hline Jashpur & 2982.82 & 3.58 \\
\hline Kanker & 2337.85 & 2.80 \\
\hline Kwardha & 3241.60 & 3.89 \\
\hline Korba & 6520.13 & 7.82 \\
\hline Koriya & 1763.77 & 2.12 \\
\hline Mahasamund & 4774.70 & 5.73 \\
\hline Raigarh & 6963.08 & 8.35 \\
\hline Raipur & $12,517.36$ & 15.01 \\
\hline Rajnandagaon & 5502.94 & 6.60 \\
\hline Surguja & 1799.44 & 2.16 \\
\hline \multirow[t]{2}{*}{ Total } & & 86.54 \\
\hline & Maharastra & \\
\hline Gadachiroli & 230 & 0.36 \\
\hline
\end{tabular}

It was found that the district Raipur contains 15.01\%, Durg 10.39, Raigarh 8.35, Bilaspur 8.09 and Korba $7.82 \%$ of upstream catchment. As these 5 districts, occupy $50 \%$ of geographical catchment, rainfall over these districts also to be carefully viewed as these may substantially influence the reservoir inflow.

The time series for month wise inflow to the reservoir is drawn for the period from 1958 to 2010 (Figures 3-7). The average inflows during these periods are in June 0.98, July 5.93, August 9.64, September 6.65 and in October 1.89 MAc ft. From the time series of June it is seen that, only 4 times an inflow of more than 4 MAc ft have occurred. From 1995 onwards inflow reduces to around $1 \mathrm{MAc} f \mathrm{ft}$ June. In July month during the year 1994, a maximum inflow of 22.98 and in 2001 inflow of 17.09 MAc ft was received, which resulted in flood. After 2001, 
Inflow in the month of June (1958-2010)

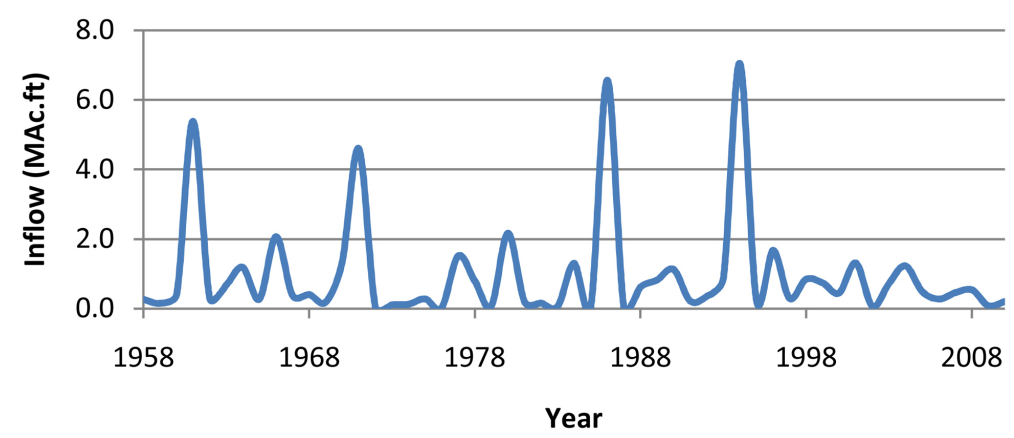

Figure 3. Timeseries of inflow to Hirakud Reservoir in the month of June.

Inflow in the month of July (1958-2010)

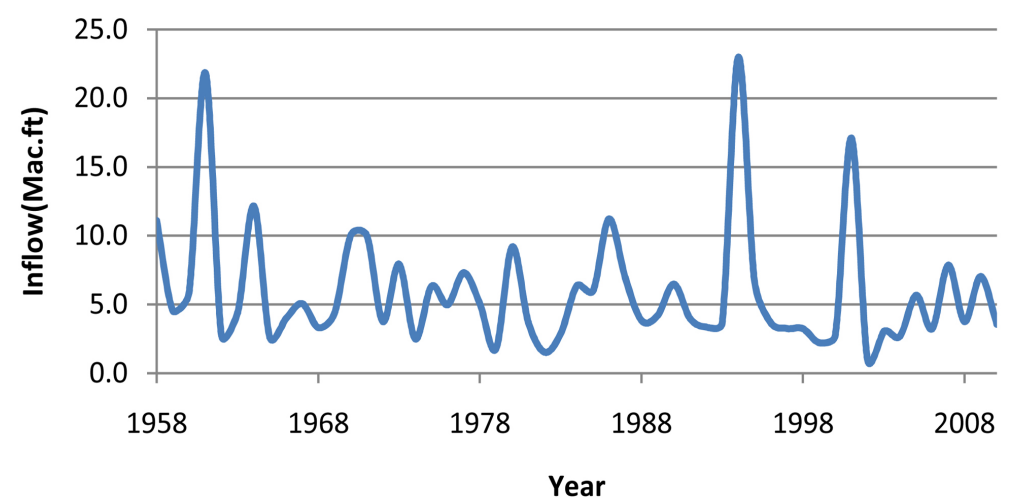

Figure 4. Timeseries of inflow to Hirakud Reservoir in the month of July.

Inflow in the month of August (1958-2010)

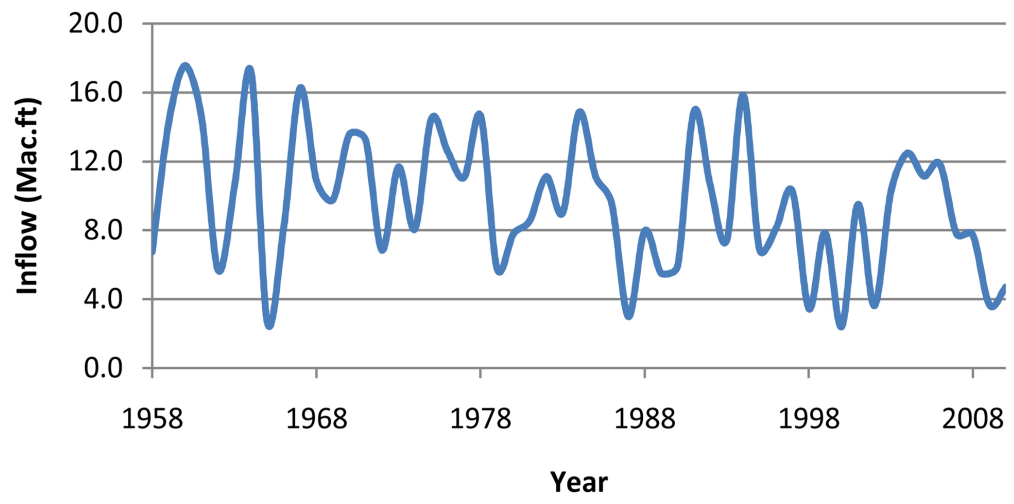

Figure 5. Timeseries of inflow to Hirakud Reservoir in the month of August.

inflow near to average was being received. In August, the inflow varies continuously. An inflow of 16.384 MAc ft was received during September 2003, which again resulted in flood. The month of October remain sensitive for flood as well as filling up of reservoir. In most of the successful monsoon years, reservoir almost attains its full capacity at the end of September. So, a higher inflow may result in flood. In 2003, an inflow of 6.207 MAc ft was received in October. 
Inflow in the month of September (1958-2010)

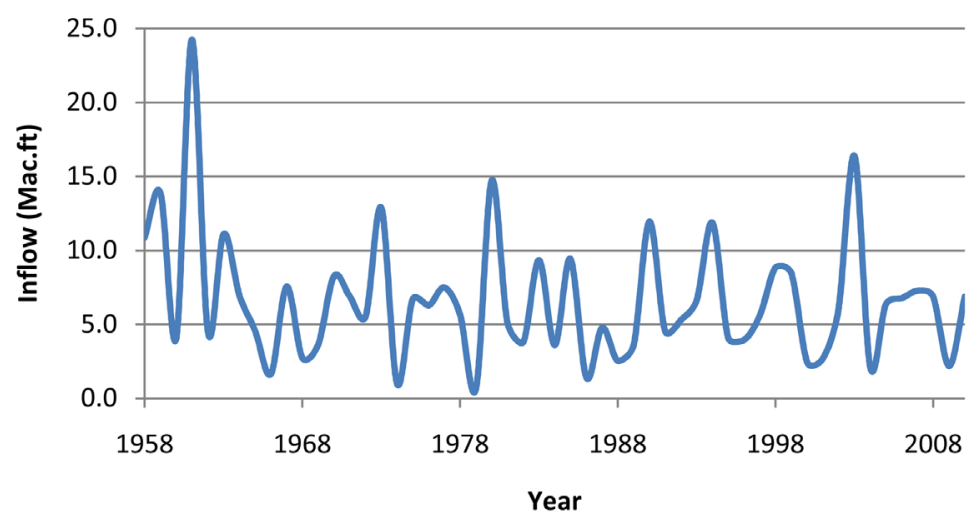

Figure 6. Timeseries of inflow to Hirakud Reservoir in the month of September.

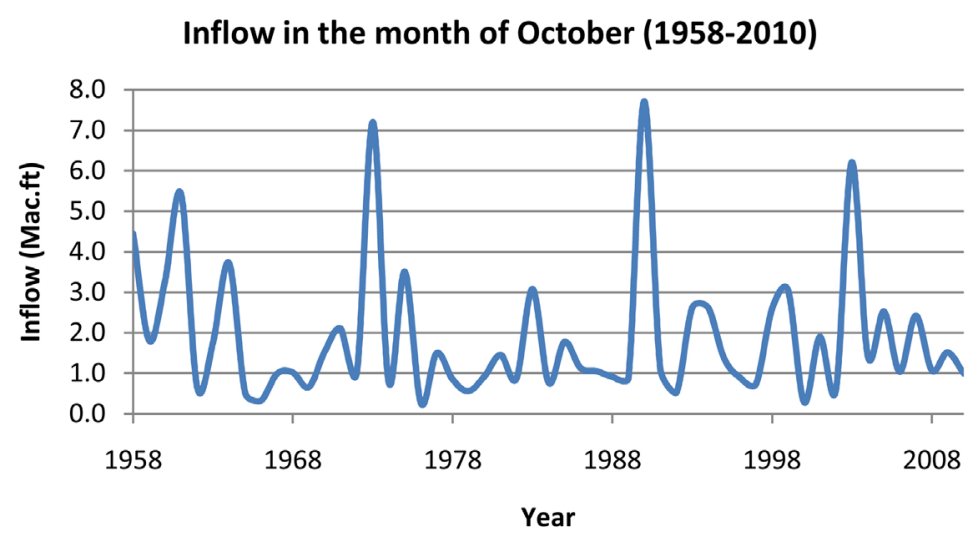

Figure 7. Timeseries of inflow to Hirakud reservoir in the month of October.

The reservoir has a live storage capacity of 3.91 MAc $\mathrm{ft}$ and major demands like Irrigation, Power, Flood control. The average inflow and demands/releases are shown in Table 2. So, the reservoir has to meet these demands as well as to control the flood or to create space for expected flood.

Applying trend analysis using Mann Kendall test, it was found that, no trends have been observed in June, September and October. In July no trend was seen at $1 \%$ and $5 \%$ significance level but a falling trend at $10 \%$. In August, no trend was seen at $1 \%$ Significance level but falling trend at $5 \%$ and $10 \%$ (Table 3 ).

For finding the frequency of rainfall first of one homogeneous region was established by applying L-moment approach. The unsuitable districts are removed from the homogeneous regional group as per the discordancy test. The districts having discordancy values more than 3 are discarded. The rainfall values of $\mathrm{Bi}$ laspur district has been discarded in all the 5 months. The suitable distributions are selected from the goodness of fit criteria. The distributions and corresponding growth factors $\left(\frac{R_{T}}{R_{m}}\right)$ are shown in Table 4. Further the inflow to dam is cal- 
culated considering all the five monsoon months for the period 1958-2010 (Table 4).

Table 2. Average inflow and demands/releases of Hirakud.

\begin{tabular}{ccccc}
\hline \multirow{2}{*}{ Month } & \multirow{2}{*}{$\begin{array}{c}\text { Average Inflow } \\
\text { (MAc.ft) }\end{array}$} & \multicolumn{2}{c}{ Average Demands/Releases (MAc.ft) } \\
\cline { 3 - 5 } & 0.98 & Irrigation & Power & Spillway \\
\hline June & 5.93 & 0.057 & 0.53 & 0.384 \\
July & 9.64 & 0.165 & 0.943 & 4.012 \\
August & 6.65 & 0.172 & 1.086 & 4.928 \\
September & 1.89 & 0.197 & 0.999 & 8.67 \\
October & & & 0.801 & 3.683 \\
\hline
\end{tabular}

Table 3. Month wise trends for inflow to reservoir at different significance level.

\begin{tabular}{ccccc}
\hline \multirow{2}{*}{ Month } & Test statistics & \multicolumn{3}{c}{ Significance Level } \\
\cline { 3 - 5 } & $(\mathbf{t})$ & $\mathbf{1 \%}$ & $\mathbf{5 \%}$ & $\mathbf{1 0 \%}$ \\
\hline June & 0.03068 & No & No & No \\
July & -1.79494 & No & No & Falling \\
August & -2.31655 & No & Falling & Falling \\
September & -0.75173 & No & No & No \\
October & 0.07671 & No & No & No \\
\hline
\end{tabular}

Table 4. Suitable regional distributions for monthly rainfall with corresponding growth factors.

\begin{tabular}{|c|c|c|c|c|c|c|}
\hline \multirow[t]{2}{*}{ Month } & \multirow{2}{*}{$\begin{array}{c}\text { Suitable } \\
\text { Regional } \\
\text { Distribution }\end{array}$} & \multicolumn{4}{|c|}{$\begin{array}{l}\text { Growth factors for } \\
\text { return periods }\end{array}$} & \multirow[t]{2}{*}{ Remark } \\
\hline & & 20 & 40 & 50 & 100 & \\
\hline \multirow{4}{*}{ June } & GEV & 1.767 & 1.945 & 1.998 & 2.155 & \multirow{4}{*}{$\begin{array}{c}\text { Region contains } 19 \\
\text { districts excluding } \\
\text { Bilaspur, Jashpur, } \\
\text { Surguja, Koriya }\end{array}$} \\
\hline & GN & 1.762 & 1.946 & 2.003 & 2.175 & \\
\hline & PT-III & 1.762 & 1.942 & 1.998 & 2.163 & \\
\hline & Wakeby & 1.78 & 1.954 & 2.004 & 2.145 & \\
\hline July & Wakeby & 1.501 & 1.654 & 1.702 & 1.851 & $\begin{array}{c}\text { Region contains } 22 \\
\text { districts except Bilaspur }\end{array}$ \\
\hline \multirow{4}{*}{ August } & GEV & 1.489 & 1.592 & 1.623 & 1.711 & \multirow{4}{*}{$\begin{array}{c}\text { Region contains } 22 \\
\text { districts except Bilaspur }\end{array}$} \\
\hline & GN & 1.486 & 1.596 & 1.63 & 1.73 & \\
\hline & PT-III & 1.486 & 1.595 & 1.628 & 1.726 & \\
\hline & Wakeby & 1.489 & 1.612 & 1.65 & 1.762 & \\
\hline September & Wakeby & 1.671 & 1.803 & 1.84 & 1.939 & $\begin{array}{c}\text { Region contains } 20 \\
\text { districts except Bilaspur, } \\
\text { Nawarangpur, Gadachiroli }\end{array}$ \\
\hline October & Wakeby & 2.446 & 2.721 & 2.796 & 2.994 & $\begin{array}{c}\text { Region contains } 22 \\
\text { districts except Bilaspur }\end{array}$ \\
\hline \multicolumn{7}{|c|}{ Inflow to Hirakud dam } \\
\hline \multirow{4}{*}{ Inflow } & GL & 2.465 & 3.184 & 3.449 & 4.406 & \multirow{4}{*}{$\begin{array}{c}\text { Taking the inflows of all } \\
\text { monsoon months for } 53 \text { years } \\
\text { observed between } 1958-2010\end{array}$} \\
\hline & GEV & 2.526 & 3.211 & 3.454 & 4.295 & \\
\hline & GN & 2.571 & 3.215 & 3.436 & 4.163 & \\
\hline & Wakeby & 2.586 & 3.255 & 3.483 & 4.24 & \\
\hline
\end{tabular}




\section{Conclusion}

The rainfall over five districts like Raipur, Durg, Raigarh, Bilaspur, Korba is very sensitive as this occupies almost $50 \%$ of the upstream catchment area. The rainfall during month of August is showing a falling trend. As most of the agricultural activities continue during this time a falling trend may hamper. The regional distributions like GEV, GN, PT-III and Wakeby are found suitable for month of June and August whereas Wake by found suitable for the month of July, September and October. The distributions GL, GEV, GN and Wakeby hold good for inflow forecasting taking the observed inflow series. The time series, trend analysis, regional fitting distributions and corresponding growth factors derived are useful for further planning and management of the reservoir operation.

\section{References}

[1] Gao, Y.C., Yao, Z.J., Liu, B.Q. and Aifeng, L.V. (2002) Evolution Trend of Miyun Reservoir Inflow and Its Motivating Factors Analysis. Progress in Geography, 21, 546-553.

[2] Dilini, W.M.N., Lyanage-Hansen, L., Attygalle, M.T.D. and Nandalal, K.D.W. (2013) Effective Water Management in the Mahaweli Reservoir System. Analyzing the Inflow of the Upmost Reservoir, International Symposium for Next Generation Infrastructure, Wollongong, October 1-4 2013.

[3] Song, A., Chandramouli, V. and Gupta, N. (2012) Analysing Inflow Trend of Indiana Reservoirs Using SOM. Journal of Hydrologic Engineering, 17, 880-887. https://doi.org/10.1061/(ASCE)HE.1943-5584.0000517

[4] Sethy, R., Pandey, B.K., Krishnan, R., Khare, D. and Nayak, P.C. (2015) Performance Evaluation and Hydrological Trend Detection of a Reservoir Under Climate Change Condition. Journal of Model Earth System Environment, 1, 2-10.

[5] Dawson, D., Van Landegham, M.M., Asquith, W.H. and Patino, R. (2015) Long Term Trends on Reservoir Water Quality and Quantity in Two Major River Basins of Southern Great Plains. Journal of Lake and Reservoir Management, 31, 254-279.

[6] Manee, D. Tachikawa, Y. and Yorozu, K. (2015) Analysis of Hydrologic Variables Changes Related to Large Scale Reservoir Operation by Using Mann-Kendall Statistical Tests in Thailand. THA 2015 International Conference on Climate Change and Water \& Environmental Management in Monsoon Asia, 28-30 January 2015, Bangkok.

[7] Halik, G., Anwar, N., Santosa, B. and Edijatno (2015) Reservoir Inflow Prediction under GCM Scenario Downscaled by Wavelet Transform and Support Vector Machine Hybrid Models. Journal of Advances in Civil Engineering, Article ID: 515376.

[8] Topaloglu, F. (2002) Determine Suitable Probability Distribution Models for Flow and Precipitation Series of the Seyhan River Basin, Turkish. Journal of Agriculture and Forestry, 26, 189-194.

[9] Balladassare, D., Castellarian, A. and Brath, A. (2006) Relationship between Statistics of Rainfall Extremes and Mean Annual Precipitation: An Application for Design-Storm Estimation in Northen Central Italy. Hydrologic \& Earth System Sciences, 10, 589-601. https://doi.org/10.5194/hess-10-589-2006

[10] Eslamian, S.S. and Feizi, H. (2007) Maximum Monthly Rainfall Analysis Using 
L-Moments for an Arid Region in Isfahan Province, Iran. Journal of Applied Meteorology and Climatology, 46, 494-503. https://doi.org/10.1175/JAM2465.1

[11] Vivekanadan, N. (2015) Rainfall Frequency Analysis using L-Moments of Probability Distribution. International Journal of Engineering Issues, 2015, 65-72.

[12] Burn, D.H. (1994) Hydrologic Effects of Climatic Change in West-Central Canada. Journal of Hydrology, 160, 53-70.

[13] Douglas, E.M., Vogel, R.M. and Kroll, C.N. (2002) Impact of Streamflow Persistence on Hydrologic Design. Journal of Hydrologic Engineering, 7, 220-228. https://doi.org/10.1061/(ASCE)1084-0699(2002)7:3(220)

[14] Yue, S. and Hashino, M. (2003) Long Term Trends of Annual and Monthly Precipitation in Japan. Journal of the American Water Resources Association, 39, 587-596. https://doi.org/10.1111/j.1752-1688.2003.tb03677.x

[15] Burn, D.H., Cunderlik, J.M. and Pietroniro, A. (2004) Hydrological Trends and Variability in the Liard River Basin. Hydrological Sciences Journal, 49, 53-67. https://doi.org/10.1623/hysj.49.1.53.53994

[16] Lindstrom, G. and Bergstrom, S. (2004) Runoff Trends in Sweden 1807-2002. Hydrological Sciences Journal, 49, 69-83.

[17] Hipel, K. and McLeod, A. (2005) Time Series Modelling of Water Resources and Environmental Systems. 45.

[18] Hosking, J.R.M. and Wallis, J.R. (1997) Regional Frequency Analysis: An Approach Based on L-Moments. Cambridge University Press, Cambridge. https://doi.org/10.1017/CBO9780511529443

[19] Rao, A.R. and Hamed, K.H. (2000) Flood Frequency Analysis. CRC Publications, New York.

[20] Government of Odisha, Department of Water Resources (2014) Flood Report of Hirakud Reservoir. 